06

\title{
Поглощение энергии в композиции диэлектрик-дисперсный проводник в зависимости от частоты сигнала
}

\author{
(C) В.А. Соцков, ${ }^{1}$ О.Г. Ашхотов, ${ }^{1,2}$ T.Т. Магкоев ${ }^{2}$ \\ ${ }^{1}$ Кабардино-Балкарский государственный университет, \\ 360004 Нальчик, Россия \\ ${ }^{2}$ Северо-осетинский государственный университет им. К.Л.Хетагурова, \\ 362025 Владикавказ, Россия \\ e-mail: oandi@rambler.ru
}

Поступило в Редакцию 23 апреля 2019 г.

В окончательной работе 19 сентября 2019 г.

Принято к публикации 16 декабря 2019 г.

\begin{abstract}
Экспериментально исследованы зависимости активного сопротивления ряда композитов диэлектрикпроводник от частоты приложенного напряжения в диапазоне менее $1 \mathrm{MHz}$. Показано, что частотная зависимость активного сопротивления в композитах диэлектрик-проводник с немагнитным материалом мала и ограничивается влиянием скин-эффекта, а в композитах с ферромагнетиком удельное сопротивление уменьшается на 1-2 порядка с увеличением частоты.
\end{abstract}

Ключевые слова: диэлектрик, проводник, частота, энергия, поглощение, проницаемость, композит, парафин, графит, оксид, железо.

DOI: 10.21883/JTF.2020.06.49285.170-19

Интерес к композитным материалам, особенно их механических и электрических свойств $[1,2]$, в мире постоянно возрастает. Большое внимание исследователи обращают на изучение процесса поглощения композитами электромагнитной энергии (ЭМЭ), которое определяется электрическими и магнитными свойствами вещества, а именно удельная электропроводность, диэлектрическая и магнитная проницаемости. Эти характеристики используются при описании процесса распространения электромагнитной волны и в общем случае являются нелинейными, тензорными, комплексными величинами. Значительный интерес, обусловленный разработкой покрытий для стелс-технологий и созданием безэховых камер [3,4], проявляется к исследованиям поглощения ЭМЭ в области СВЧ. Однако для диапазона электромагнитных колебаний менее $1 \mathrm{MHz}$ поглощение ЭМЭ исследовано недостаточно полно при том, что для разработки электронных приборов такие сведения могут оказаться первостепенными.

Целью настоящей работы является экспериментальное исследование зависимости величины активного сопротивления от частоты для композита диэлектрик-проводник и исследование на этой основе процесса поглощения электромагнитной энергии на частотах до $1 \mathrm{MHz}$. При проведении исследований в композите использовались парафин нефтяной твердый П2 ГОСТ 23683-89 и два вида проводников магнитный - железо-, „Ч“, и немагнитный - графит (термографит - препарат коллоидно-графитовый сухой С-1 ТУ 113-08-48-63-90).

Гранулометрический состав порошков определялся методом произвольных выборок под микроскопом и представлен в таблице.
Использование в качестве проводящей компоненты графита с точки зрения минимизации контактного сопротивления имеет ряд преимуществ по сравнению с металлами. Окислы углерода - это газы и вне зависимости от происхождения графита можно не рассматривать образование оксидной пленки на частицах. Железо же имеет на поверхности оксид и его удельное сопротивление в композите на несколько порядков выше, чем у графита при тех же концентрациях [5]. Поскольку парафин - насыщенный углеводород, а температура образца в процессе изготовления не превышала $55^{\circ} \mathrm{C}$, то в исследуемой системе не возникает промежуточных соединений [5]. Таким образом, анализ подобных образцов позволяет рассчитывать на разделение влияния на проводимость электрической и магнитной составляющей.

В качестве диэлектрической матрицы использовался парафин, удельное сопротивление которого составляло $\rho=3 \cdot 10^{10} \Omega \cdot \mathrm{m}$. Электродами служили медные пластины $15 \cdot 10 \mathrm{~mm}$, расположенные на расстоянии $9 \mathrm{~mm}$. Измерения производились на измерителе импеданса Е7-20 и тераомметре Е6-13 при 293 К. Методика изготовления образцов, электрических измерений была аналогична методикам, описанным в работе [5]. Для устранения влияния размерных эффектов при исследовании оценивалось удельное сопротивление композитов.

На рис. 1 изображены зависимости удельного сопротивления $\rho$ от логарифма частоты $f$ для чистого парафина и системы парафин-графит с объемными концентрациями графита $X=10$ и $30 \mathrm{wt} \%$. Известно [6], что для чистого парафина потери электромагнитной энергии обусловлены в основном релаксацией молекул парафина. Как видно из рис. 1 (кривая 1) наибольшее удельное сопротивление у чистого парафина, и этот 
Гранулометрический состав порошков, использованных в настоящей работе

\begin{tabular}{l|c|c}
\hline \multicolumn{1}{c|}{ Параметры } & $\begin{array}{c}\text { Термографит } \\
\text { С-1 }\end{array}$ & $\begin{array}{c}\text { Железо } \\
\text {,“棌 }\end{array}$ \\
\hline Основные размеры диаметров частиц, $\mu \mathrm{m}$ & $3-5$ & $4-6$ \\
Содержание основной группы частиц, \% & 70 & 80 \\
Максимальные размеры диаметров частиц, $\mu \mathrm{m}$ & $5-12$ & $6-10$ \\
Содержание частиц с максимальными размерами, \% & 10 & 5 \\
Минимальные размеры диаметров частиц, \% & $2-3$ & $0.7-4$ \\
Содержание частиц с минимальными размерами,\% & 20 & 15
\end{tabular}

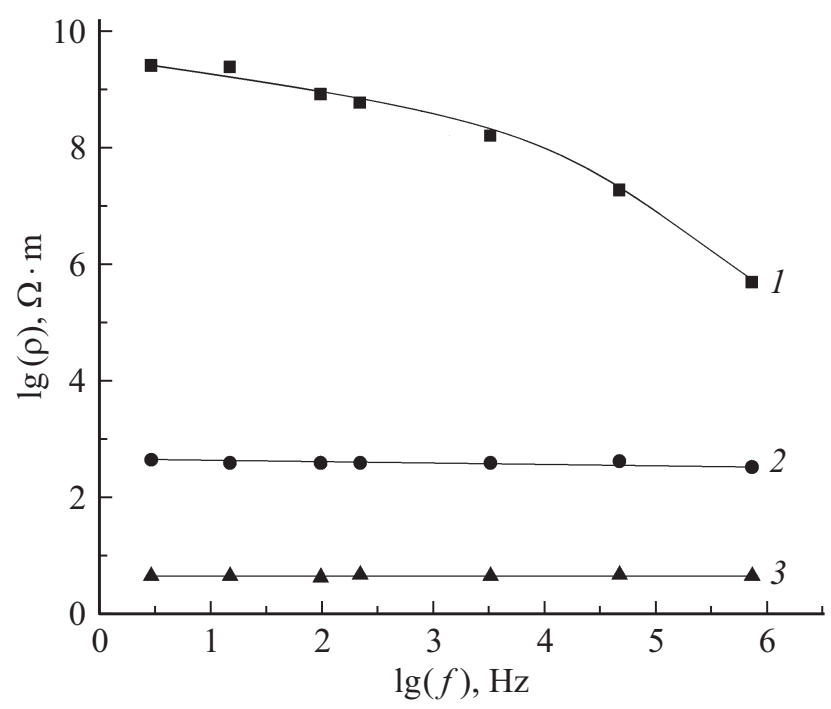

Рис. 1. Зависимость логарифма удельного сопротивления парафина и композита парафин-графит от логарифма частоты: 1 - парафин, 2 - парафин с графитовым наполнителем $(X=10 \mathrm{wt} . \%), 3-$ парафин с графитовым наполнителем $(X=30 \mathrm{wt} . \%)$.

параметр для композита резко уменьшается при увеличении концентрации графита. Столь резкое изменение удельного сопротивления в композите парафин-графит при введении графита $(X=10 \mathrm{wt} \%$, кривая 2 на рис. 1) может быть объяснено следующим образом. При концентрациях проводника в парафиновой матрице до порога перколяции в образце нет проводящих цепей, которые соединяют электроды, но существуют сплошные скопления частиц проводника и другие стохастические пространственные структуры, которые резко снижают сопротивление композита. В образовавшихся пространственных структурах сопротивление зависит не только от сопротивления самой проводящей частицы, но и от контактного сопротивления между частицами. В итоге образуются несквозные проводящие структуры, возникающие до порога перколяции. При концентрациях проводника свыше порога перколяции ( $X=30 \mathrm{wt} . \%$, кривая 3 на рис. 1) к уже образованным структурам добавляются сквозные проводящие цепи, которые еще снижают сопротивление композита.
На рис. 2 приведена логарифмическая зависимость удельного сопротивления композита парафин-железо от $\lg (f)$. Видно, что, начиная примерно с частоты $1 \mathrm{kHz}$, наблюдается резкое уменьшение сопротивления (рис. 2, кривая 1), причем увеличение концентрации железа приводит к более пологой зависимости $\lg \rho=\varphi(\lg f)$ (рис. 2, кривая 2). Сравнивая рис. 1 и 2 можно отметить, что при введении графита в парафин частотная зависимость неочевидна, а для ферромагнетика наблюдается ярко выраженная зависимость.

Пологий ход кривой 2 на рис. 2 можно объяснить следующим образом. Потери энергии, а следовательно, и активное сопротивление в электрической цепи при переменном токе всегда больше потерь энергии в этой же цепи при постоянном токе. Причина этого заключается в том, что в цепях переменного тока потери энергии обусловлены не только обычным омическим сопротивлением проводников по закону Джоуля-Ленца, но и многими другими причинами $[3,4,7]$ : поляризацией, потерями на гистерезис, излучением, скин-эффектом, индукционными токами Фуко и т.д. Мощность, обусловленная потерями на вихревые токи, определяется

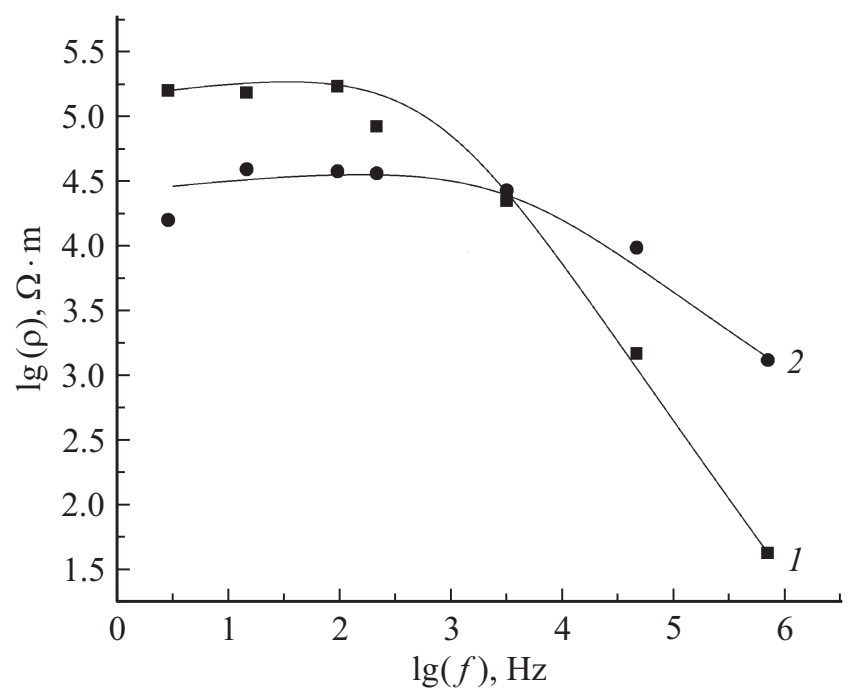

Рис. 2. Логарифмическая зависимость удельного сопротивления композита парафин-железо от $\lg (f): 1$ - наполнитель $X_{\mathrm{Fe}}=10 \mathrm{wt} . \%, 2-$ наполнитель $X_{\mathrm{Fe}}=60 \mathrm{wt} . \%$. 


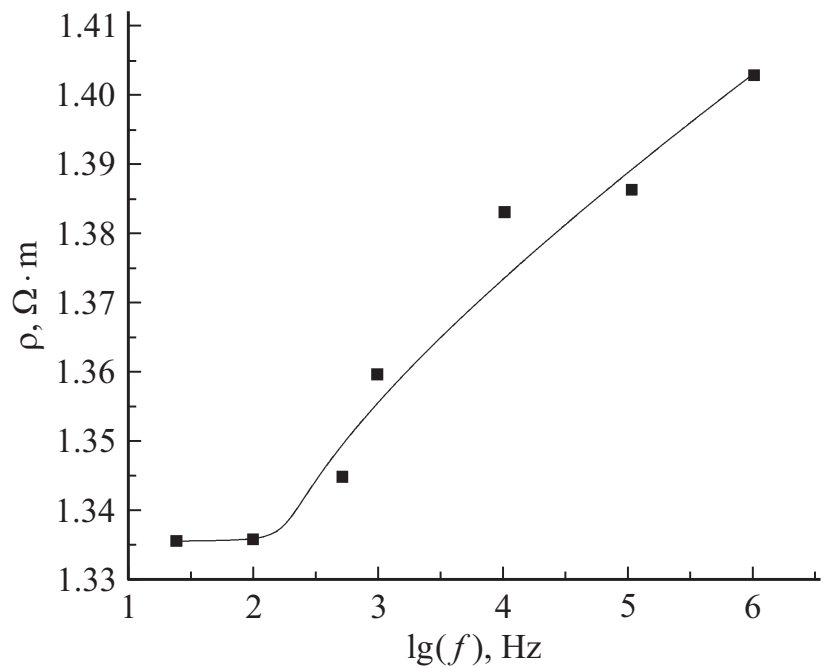

Рис. 3. Зависимость удельного сопротивления композита парафин-графит $(X=40 \mathrm{wt} . \%)$ от логарифма частоты.

эмпирической формулой [6]

$$
P=\varsigma f^{2} B_{m}^{2} V
$$

где $\varsigma-$ коэффициент, пропорциональный удельной проводимости вещества и зависящий от геометрической формы и размеров поперечного сечения намагниченного образца; $V$ - объем ферромагнетика; $f$ - частота; $B-$ магнитная индукция.

Потери мощности на гистерезис пропорциональны частоте в первой степени, поэтому при высоких частотах учитывают в первую очередь потери на вихревые токи. С увеличением концентрации ферромагнетика изменение не столь велико, что, вероятно, связано со значительным уменьшением омического сопротивления, поэтому потери на гистерезис и вихревые токи уходят на второй план, несмотря на рост $\varsigma$ и $V$.

В настоящей работе также анализировался скинэффект, который при увеличении частоты обычно приводит к росту активного сопротивления. Для наблюдения скин-эффекта характеристики $\lg (\rho)=\varphi(\lg (f))$ рассматривались при объемной концентрации проводящего компонента $X>X_{c}$, где $X_{c}-$ порог перколяции в данном композите. Влияние скин-эффекта исследовалось на композите парафин-графит (рис. 3), как на объекте с наиболее выраженным эффектом. Порог перколяции для композита парафин-графит $X_{c}=16 \mathrm{wt} . \%$ [5], поэтому была выбрана концентрация графита $X=40$ wt.\%. Действительно, удельное сопротивление (рис. 3) возрастает с увеличением частоты, что говорит об образовании сквозных проводящих цепей и влиянии скин-эффекта. Увеличение сопротивления (рис. 3) с частотой не велико и составляет около 5\% в рассматриваемом диапазоне частот. Однако этот эффект четко выражен и наблюдается при любых концентрациях проводника $X>X_{c}$.

Таким образом, проведенные исследования показали, что:
- для композитов с ферромагнетиком с увеличением частоты удельное сопротивление может уменьшаться на 1-2 порядка;

- частотная зависимость активного сопротивления в композитах диэлектрик-проводник с немагнитным материалом мала и ограничивается влиянием скин-эффекта.

\section{Финансирование работы}

Работа выполнена в рамках проекта № 2019-220-078022 Минобрнауки РФ.

\section{Конфликт интересов}

Авторы заявляют, что у них нет кофликта интересов.

\section{Список литературы}

[1] Su Ya-nan, Zhang Shou-chun, Zhang Xing-hua // New Carbon Mater. 2017. N 4. P. 152-156.

[2] Харитонов Е.В. Диэлектрические материалы с неоднородной структурой. М.: Радио и связь, 1983. 128 с.

[3] Елсуков К.П., Розанов К.Н., Ломаева С.Ф., Осипов А.В., Петров Д.А., Старостенко С.Н., Шуравин А.С., Ульянов А.Л., Чулкина А.А., Сурнин Д.В. // ЖТФ. 2009. Т. 79. Вып. 4. С. 125-130.

[4] Казанцева Н.Е., Рывкина Н.Г., Чмутин И.А. // Радиотехника и электроника. 2003. Т. 48. № 2. С. 196-201.

[5] Сочков В.А. // ФТП. 2005. Т. 39. Вып. 2. С. 269-275.

[6] Пасынков В.В. Материалы электронной техники. М.: Высшая школа, 1980. $155 \mathrm{c}$.

[7] Герасимов В.Г., Кузнецов Э.В., Николаева О.В. Электротехника и электроника. Кн. 1. Электрические и магнитные цепи. М.: Энергоатомиздат, 1996. 288 с. 